Abstracta Iranica Abstracta Iranica

Revue bibliographique pour le domaine irano-aryen

Volume 40-41 | 2019

Comptes rendus des publications de 2017-2018

\title{
Amir Harrak. The Chronicle of Zuqnin, Parts I and II: From the Creation to the Year 506/7 AD
}

\section{Christelle Jullien}

\section{(2) OpenEdition}

12 Journals

\section{Édition électronique}

URL : http://journals.openedition.org/abstractairanica/50900

DOI : 10.4000/abstractairanica.50900

ISBN : 1961-960X

ISSN : 1961-960X

Éditeur :

CNRS (UMR 7528 Mondes iraniens et indiens), Éditions de l'IFRI

Référence électronique

Christelle Jullien, "Amir Harrak. The Chronicle of Zuqnin, Parts I and II: From the Creation to the Year 506/7 AD», Abstracta Iranica [En ligne], Volume 40-41 | 2019, document 6, mis en ligne le 30 décembre 2019, consulté le 24 avril 2021. URL : http://journals.openedition.org/abstractairanica/50900 ; DOI : https://doi.org/10.4000/abstractairanica.50900

Ce document a été généré automatiquement le 24 avril 2021.

Tous droits réservés 


\title{
Amir Harrak. The Chronicle of Zuqnin, Parts I and II: From the Creation to the Year 506/7 AD
}

\author{
Christelle Jullien
}

\section{RÉFÉRENCE}

Amir Harrak. The Chronicle of Zuqnin, Parts I and II: From the Creation to the Year 506/7 AD. (Gorgias Chronicles of Late Antiquity 2), Piscataway, New Jersey: Gorgias Press, 2017, 539 p. ISBN 978-1-4632-0663-5

1 Cet ouvrage constitue la suite logique des travaux de l'A. qui a déjà travaillé sur ce texte majeur de la littérature apocalyptique syriaque en en publiant les parties III et IV (The Chronicle of Zuqnîn, parts III and IV : A.D. 488-775. Translated from Syriac with notes and introduction, [Mediaeval Sources in Translation 36], Toronto: Pontifical Institute of Mediaeval Studies, 1999). Il propose ici la première traduction anglaise des premières et secondes parties dans une édition à jour qui inclut aussi la lettre dédicatoire de l'écrivain, ainsi que le texte syriaque. La Chronique de Zuqnīn, appelée aussi de façon moins appropriée Chronique du Pseudo-Denys de Tell-Mahrēe, est une histoire universelle qui s'échelonne depuis la création du monde jusqu'à la période de rédaction, dans les années 775-776. Il est désormais admis que l'auteur en est Josué le stylite, contemporain des califes al-Manșūr et al-Mahdī, qui vécut au monastère de Zuqnīn près d'Amid. Dans les deux parties objets de cette édition, l'A. remarque à juste titre que certaines sources sont aujourd'hui perdues et n'ont été conservées que dans cette chronique sous une forme réduite et compilée. En ce qui concerne plus proprement l'empire sassanide, on relèvera la présence de la Caverne des trésors, recueil de traditions relatives à l'histoire biblique dont l'arrière-fond iranien a été bien relevé, notamment par les études récentes de S. Minov. La courte chronique de Josué le Stylite, également 
insérée dans le texte, traite des relations romano-perses à la fin du V $\mathrm{V}^{\mathrm{e}}$-début du $\mathrm{VI}^{\mathrm{e}}$ siècle.

AUTEURS

CHRISTELLE JULLIEN

CNRS, Mondes iranien et indien, Paris 